\title{
Effects of in Utero and Lactational Exposure to Di(2-ethylhexyl)phthalate on Somatic and Physical Development in Rat Offspring
}

\author{
Kenichi KOBAYASHI*, Muneyuki MIYAGAWA, Rui-Sheng WANG, Megumi SUDA, \\ Soichiro SEKIGUCHI and Takeshi HONMA
}

National Institute of Occupational Safety and Health, 21-1, Nagao 6-chome, Tama-Ku, Kawasaki 214-8585, Japan

Received March 27, 2006 and accepted July 3, 2006

\begin{abstract}
Di(2-ethylhexyl)phthalate (DEHP) has been reported to act as an antiandrogen and to affect the reproductive organs and accessory genital glands. Thus, to assess the reproductive toxicity of DEHP it is important to examine both its adverse effects on the development of offspring following maternal exposure and its effects on sexual function and fertility. In the present study, we examined whether in utero and lactational exposure to DEHP affects postnatal somatic growth of offspring in the rat. Pregnant females were orally administered various doses of DEHP $(0,25,100$ or $400 \mathrm{mg} / \mathrm{kg}$ body weight/day) from gestational day (GD) 6 through postnatal day (PND) 20. There were no significant changes in body weight, body length, tail length, or the weight of individual organs between the control and DEHP-treated groups. Somatic hormonal parameters were the same for all DEHP doses. These findings suggest that in utero and lactational exposure to various concentrations of DEHP has very little effect on postnatal development or endocrine and physical status of male and female rat offspring under the experimental conditions of the present study.
\end{abstract}

Key words: Di(2-ethylhexyl)phthalate, Postnatal development, In utero and lactational exposure, Offspring, Rat

\section{Introduction}

To date, several compounds have been suspected of exerting endocrine-disturbing effects even at ultra-low concentrations. Phthalates have been produced and used in the manufacture of chemically derived materials and products. Di(2-ethylhexyl)phthalate (DEHP) has been most widely used in polyvinyl chloride to impart structural flexibility, and it is used as a plasticizer in products such as food packaging, children's products (toys and crib bumpers) and medical devices. Significantly, DEHP has been detected in plasma samples ${ }^{1}$. Mono(2-ethylhexyl)phthalate (MEHP), which is an active and the predominant DEHP metabolite, is also considered as a testicular toxicant ${ }^{2}$. It has been estimated that mean DEHP intake is $8.2 \mu \mathrm{g} / \mathrm{kg}$ body weight per day for adults ${ }^{3)}$. During recent years, DEHP has been

*To whom correspondence should be addressed. excluded from many products to avoid consumer exposure. However, recent heightened public concerns about environmental exposure to high concentrations of DEHP have raised new questions about its possible occupational and medical health hazards.

Developmental toxicity studies of DEHP have been conducted in laboratory mice ${ }^{4-8)}$ and rats ${ }^{8-10)}$. These reports suggest that in utero exposure to high doses of DEHP induces embryotoxicity and/or teratogenicity. Animal reproductive toxicity studies of DEHP have also been reported. In a study of adult male rats, testicular defects such as atrophy of the seminiferous tubules, loss of spermatogenesis and vacuolation of Sertoli cells were observed after 90 days of dietary exposure to DEHP at 500 and 5,000 ppm (equivalent to 37.6 and $375.2 \mathrm{mg} / \mathrm{kg} /$ day, respectively) ${ }^{11)}$. Perinatal exposure to DEHP in rats from gestational day (GD) 14 through postnatal day (PND) 3 reduced anogenital distance, testis weight or the weight of androgen-dependent tissues ${ }^{12}$. 
Dietary exposure of adult male rats given $0,320,1,250$, 5,000, and 20,000 ppm DEHP (equivalent to 0, 17.5, 69.2, 284.1 and $1156.4 \mathrm{mg} / \mathrm{kg} /$ day, respectively) for 60 days, when mated with untreated adult females, did not affect the rate of neonatal death, initial pup weight or growth (up to PND 7), whereas the average litter size decreased in rats fed 20,000 ppm DEHP ${ }^{13)}$. Inhalation exposure of adult male Wistar rats to $25 \mathrm{mg} / \mathrm{m}^{3}$ for $6 \mathrm{~h} /$ day for $8 \mathrm{wk}$ increased plasma testosterone level and seminal vesicle weight in a dosedependent manner ${ }^{14)}$. In a study of adult female rats, DEHP induced prolonged estrous cycles and suppressed plasma concentrations of estradiol and subsequent ovulation ${ }^{15}$.

Several studies have shown that in utero and lactational exposure to DEHP leads to abnormalities in the hypothalamus-pituitary-testicular axis. Sprague-Dawley rats were orally dosed with DEHP $(0-1,500 \mathrm{mg} / \mathrm{kg} /$ day $)$ from GD 3 through PND 21, and dose-related effects in the male offspring included several parameters involved in sexual development ${ }^{16)}$. Oral exposure of pregnant female LongEvans rats to $100 \mathrm{mg} / \mathrm{kg} /$ day DEHP from GD 12-21 induced significantly increased levels of testosterone and luteinizing hormone in male offspring on PND 21 and PND 35, but by PND 90 the levels were comparable between treated and untreated animals ${ }^{17)}$, indicating that the magnitude of DEHP toxicity on reproductive function is influenced by the stage of development.

Thus, DEHP toxicity studies in laboratory animals have focused on embryotoxicity, teratogenicity and reproductive toxicological effects in addition to some developmental effects in the early postnatal period, yet extensive toxicity information for long-term development after DEHP exposure is still lacking. The purpose of the present study was to evaluate postnatal growth and physical development following in utero and lactational exposure to DEHP in male and female rat offspring until the post-pubertal period. We examined the effects of DEHP on pubertal development, and doses of DEHP were chosen based on the levels that caused no overt maternal toxicity. Additionally, the exposure period was extended to examine the effects of lactational exposure in addition to the effects of in utero exposure, to complement previous studies ${ }^{4-10}$. Thus, we administered several doses of DEHP orally by gavage to pregnant rats using an experimental schedule identical to one used previously ${ }^{18)}$, and we examined the effects on postnatal somatic and organ growth, as assessed by body weight, body length, tail length and main organ weights, including reproductive organs, in male and female offspring. In addition, to better assess physical status following DEHP exposure, we evaluated the levels of several plasma hormonal landmarks with regard to postnatal somatic growth.

\section{Materials and Methods}

\section{Chemicals and experimental animals}

DEHP (purity >99.9\%, Cat\# 289-10442) and corn oil were obtained from Wako Pure Chemical Industries, Ltd., Osaka, Japan. A total of 52 pregnant (GD 3) female rats (Crj: CD (SD) IGS strain, $9 \mathrm{wk}$ of age) were purchased from Charles River Japan, Inc. (Tsukuba, Japan). The presence of a copulatory plug defined GD 0 . They were acclimated on GD 3-6 and housed individually in plastic cages with sterilized wood chips (Soft chip, Japan Slc Inc., Shizuoka, Japan) for bedding and were maintained under controlled temperature $\left(23 \pm 1^{\circ} \mathrm{C}\right)$ and humidity $(55 \pm 5 \%)$ and with a 12-h light-dark cycle (08:00-20:00) throughout the study. A standard laboratory diet (CE-2, Clea Japan, Inc., Tokyo, Japan) and drinking water were available ad libitum.

\section{Dose range-finding evaluation}

Dams were randomly divided into five groups (four pregnant females per group). The DEHP-exposed groups were orally administered 500, 1,000, 1,500, or 2,000 mg DEHP/kg/day in corn oil vehicle $(10 \mathrm{ml} / \mathrm{kg}$ of body weight); DEHP was given between 08:30 and 09:30 for five consecutive days each week (Monday-Friday) from GD 6 through GD 20, and the control group was given the same amount of corn oil during the same period. During the exposure period, we recorded maternal body weights and noted any clinical signs or abnormal behavior that may have resulted from toxic effects. These results were used to determine the range of the DEHP dose for the main study.

\section{Main study}

Dams were randomly divided into four groups (eight pregnant females per group) and weighed once daily from GD 3 through PND 20 (except for GD 4 and 5). The DEHPexposed groups were orally administered 25,100 or 400 $\mathrm{mg}$ DEHP/kg/day in corn oil vehicle $(10 \mathrm{ml} / \mathrm{kg}$ of body weight); DEHP was given between 08:30 and 09:30 from GD 6 through PND 20, and the control group was given the same amount of corn oil during the same period. Maternal data were recorded as described above. For each dam, the gestational duration was recorded, and weight gain during gestation and lactation was measured. Dams were checked for birth until 10:00 on each day; the day on which pups were first observed was designated PND 0 . The number of 
live births and the weight of each live pup on PND 1 were recorded. The litter size was standardized to 10 (five males and five females when possible) between 10:00 and 11:00 on PND 7 (1 wk of age). Litters with a total of nine or fewer pups were not culled regardless of the sex ratio. Culled pups were used for the analysis at 1 wk of age. On PND 21, the remaining offspring were weaned, and thereafter males and females were housed in separate stainless steel cages by litter. Body weights were recorded with an electric balance (Shimadzu, Kyoto, Japan). Body length and tail length (millimeters) were measured with a digital caliper (Mitutoyo, Kanagawa, Japan). The nose-anus length was considered the body length. One male and one female offspring from each dam were dissected at 3 and 9 wk of age when possible. While the rat was under ether anesthesia, liver, kidneys and testes, prostate and seminal vesicles or ovaries and uterus were carefully removed and weighed.

\section{Hormone determinations}

For hormone determinations, blood samples were collected from the postcaval vein following euthanasia by ether inhalation at $9 \mathrm{wk}$ of age. Plasma samples were obtained by centrifugation at $4^{\circ} \mathrm{C}$ and stored at $-20^{\circ} \mathrm{C}$ until the analysis. Concentrations of the plasma thyroid hormones thyroxine $\left(\mathrm{T}_{4}\right)$ and tri-iodothyronine $\left(\mathrm{T}_{3}\right)$ were determined by a timeresolved fluoroimmunoassay (DELFIA $\mathrm{T}_{4}$ Reagents and DELFIA $\mathrm{T}_{3}$ Reagents, respectively, PerkinElmer Life and Analytical Sciences, Inc., MA, USA). Plasma growth hormone $(\mathrm{GH})$ concentrations were determined by enzyme immunoassay (EIA) (Rat GH EIA Biotrak system, GE Healthcare Bio-Sciences Corp., NJ, USA). Plasma insulinlike growth factor-I (IGF-I) concentrations were also measured by EIA (ACTIVE mouse/rat IGF-I EIA kit, Diagnostic Systems Laboratories, Inc., TX, USA). Timeresolved fluorescence and absorbance were measured by a multilabel counter (VICTOR ${ }^{2}$, PerkinElmer Life and Analytical Sciences, Inc.). All hormones were assayed according to the manufacturer's instructions.

\section{Statistical analysis}

The differences from the corresponding control group were statistically analyzed by an analysis of variance followed by Dunnett's test (significance at $p<0.05$ ).

\section{Results}

\section{Dose range-finding evaluation}

In the $1,000 \mathrm{mg} / \mathrm{kg} /$ day and higher DEHP groups, maternal toxicity was clearly manifested as greatly suppressed weight gain during gestation, which led us to discontinue subsequent dosing by GD 17 of this preliminary study. In the $500 \mathrm{mg} /$ $\mathrm{kg}$ /day group, mean body weights decreased slightly at later stages of gestation compared with the control group (data not shown). Based on these observations, we set the highest dose at $400 \mathrm{mg} / \mathrm{kg} /$ day to exclude the influence of maternal toxicity and observe the effect of DEHP on the offspring. The lowest dose and the middle dose were set at $25 \mathrm{mg} / \mathrm{kg} /$ day and $100 \mathrm{mg} / \mathrm{kg} /$ day, respectively.

\section{Main study \\ Dams}

Table 1 shows the number of dams and their offspring used for examinations in each group. Weight gain did not differ between dams from the control group and the DEHP groups from GD 6 through GD 21. In the $400 \mathrm{mg} / \mathrm{kg} /$ day group, one dam was found dead on GD 23, and thus the dam was excluded from the analysis. No significant differences were observed between the control group and the DEHP groups with regard to gestational duration or the number of live births per litter on PND 1.

Figure 1 shows maternal body changes during gestation (left panel) and lactation (right panel). There were no statistically significant differences among groups with regard to maternal body weight during the gestation and lactation periods, although the $25 \mathrm{mg} / \mathrm{kg} /$ day group showed a transient but not significant weight reduction during early lactation.

\section{Offspring}

The number of offspring examined is shown in Table 2. In male and female offspring, there were no statistically significant differences in body weight, body length or tail length between the control and DEHP-exposed groups at 1 , 3 or 9 wk of age (Figs. 2, 3 and 4). There were no statistically significant effects on liver or kidney weights in males or females at 1, 3 or 9 wk of age (Table 3,4). In male offspring, testis weights did not differ among the control group and DEHP groups at 3 or $9 \mathrm{wk}$ of age (Table 3). Prostate and seminal vesicle weights did not differ among the control group and DEHP groups at 9 wk of age (Table 3). In female offspring, ovary and uterus weights did not differ among the groups at 3 or 9 wk of age (Table 4).

\section{Physical status of offspring}

In male offspring, no statistically significant differences in plasma concentrations of $\mathrm{T}_{4}, \mathrm{~T}_{3}, \mathrm{GH}$ or IGF-I were observed among the control group and the DEHP groups at 9 wk of age (Table 5). In female offspring, no statistically significant differences in plasma concentrations of $\mathrm{T}_{4}, \mathrm{~T}_{3}$, 
Table 1. Dams and litter data

\begin{tabular}{lcccc}
\hline & \multicolumn{4}{c}{ DEHP dose $(\mathrm{mg} / \mathrm{kg} /$ day $)$} \\
\cline { 2 - 5 } & 0 & 25 & 100 & 400 \\
\hline Females (n) & 8 & 8 & 8 & 8 \\
Pregnant females (n) & 8 & 8 & 8 & 8 \\
Dam weight gain (GD 6-21) & $130 \pm 7^{\mathrm{a}}$ & $127 \pm 5$ & $135 \pm 4$ & $133 \pm 5$ \\
Gestational period (days) & $21.1 \pm 0.1$ & $21.4 \pm 0.2$ & $21.3 \pm 0.2$ & $21.3 \pm 0.2$ \\
Live births/litter on PND 1 & $11.8 \pm 0.7$ & $13.6 \pm 0.6$ & $13.5 \pm 0.5$ & $11.7 \pm 0.5(7)^{\mathrm{b}}$ \\
\hline
\end{tabular}

${ }^{a}$ Values are mean \pm SEM.

${ }^{\text {b}}$ The number in parentheses represents dams per dose group. One dam was found dead on GD 23 , and thus the dam was excluded from the analysis.
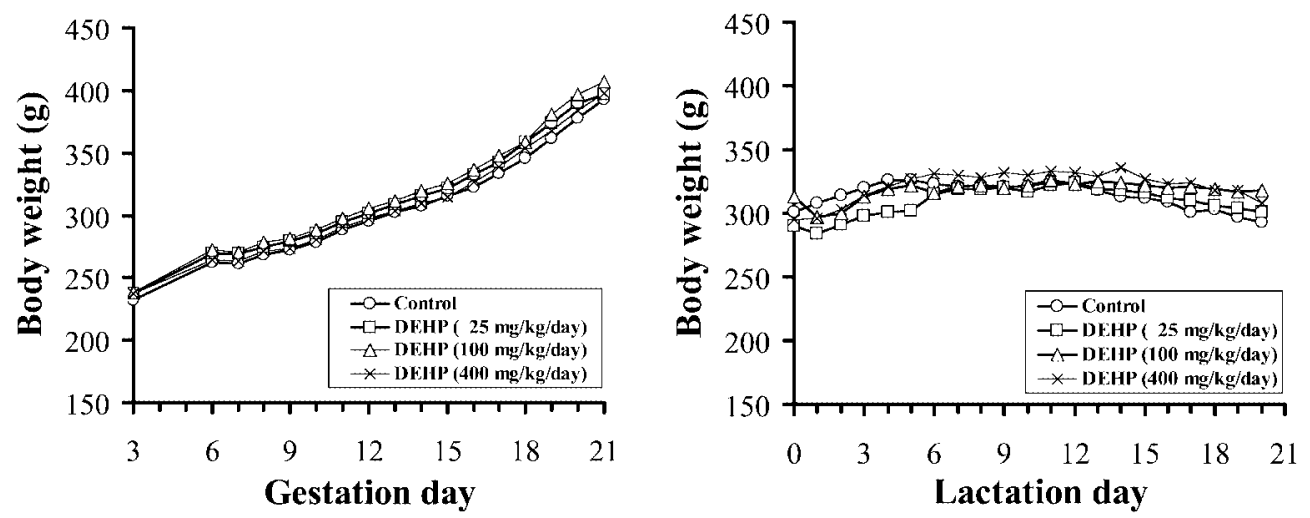

Fig. 1. Effects of exposure to di(2-ethylhexyl)phthalate (DEHP) on maternal body weight during gestation (left panel) and lactation (right panel).

Each point represents the mean.

GH or IGF-I were observed between the control group and the DEHP groups at 9 wk of age (Table 6).

\section{Discussion}

In recent years, the issue of endocrine-disrupting chemicals has been the topic of much discussion. Nagel et al. ${ }^{19)}$ and vom Saal et al. ${ }^{20)}$ reported that in utero exposure to low doses of bisphenol A ( 2 and $/$ or $20 \mu \mathrm{g} / \mathrm{kg} / \mathrm{day}$ ) affects prostate and preputial gland weight and decreases daily sperm production efficiency in mouse offspring; moreover, their results indicated that exposure to low doses of xenoestrogens during a critical period can affect the reproductive organ systems of male offspring. On the other hand, other investigators have failed to find such effects in mouse offspring when using an identical experimental design ${ }^{21,22)}$. Thus, the issue of low-dose exposure to these potential endocrine-disrupting chemicals remains a matter of debate among investigators. Hence, as more refined analytical methods become available, risk assessment for previously characterized chemical
Table 2. Number of subjects examined

\begin{tabular}{lclccr}
\hline \multirow{2}{*}{ Group } & $\begin{array}{c}\text { DEHP dose } \\
(\mathrm{mg} / \mathrm{kg} / \mathrm{day})\end{array}$ & \multicolumn{4}{c}{ No. of offspring examined } \\
\cline { 3 - 6 } & & Age (wk) & 1 & 3 & 9 \\
\hline \multirow{2}{*}{ Control } & \multirow{2}{*}{0} & Male & 8 & 8 & 8 \\
& \multirow{2}{*}{ DEHP } & Female & 6 & 8 & 8 \\
& \multirow{2}{*}{ DEHP } & Male & 10 & 7 & 7 \\
& \multirow{2}{*}{ DEHP } & Female & 11 & 7 & 7 \\
& \multirow{2}{*}{400} & Male & 13 & 8 & 7 \\
& & Female & 9 & 8 & 8 \\
& & Male & 9 & 7 & 6 \\
& & Female & 7 & 7 & 7 \\
\hline
\end{tabular}

substances should be repeated.

Embryo-fetotoxicity and teratotoxicity of DEHP have been studied in mice ${ }^{4-8)}$ and rats ${ }^{8-10)}$. These studies were conducted to elucidate whether in utero exposure to high doses of DEHP induces embryotoxicity and/or teratogenicity. The doses used in these previous studies were far in excess of human 

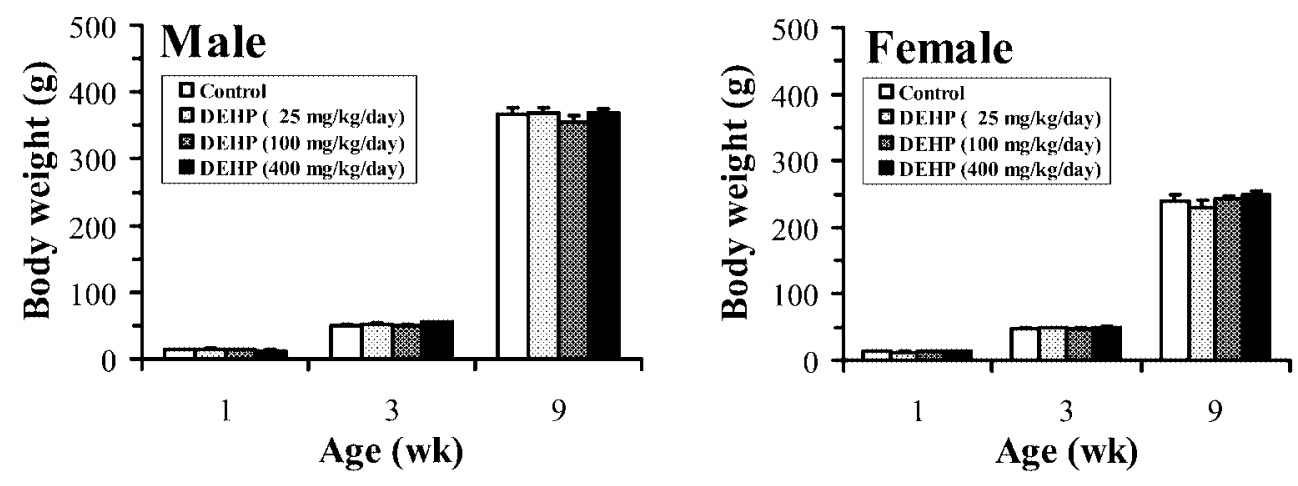

Fig. 2. Effects of maternal exposure to DEHP on postnatal body weight of offspring.

Body weights of male (left panel) and female (right panel) offspring are shown at 1,3 and 9 wk of age. Each column and vertical bar represent the mean and SEM, respectively. There were no significant differences among groups.
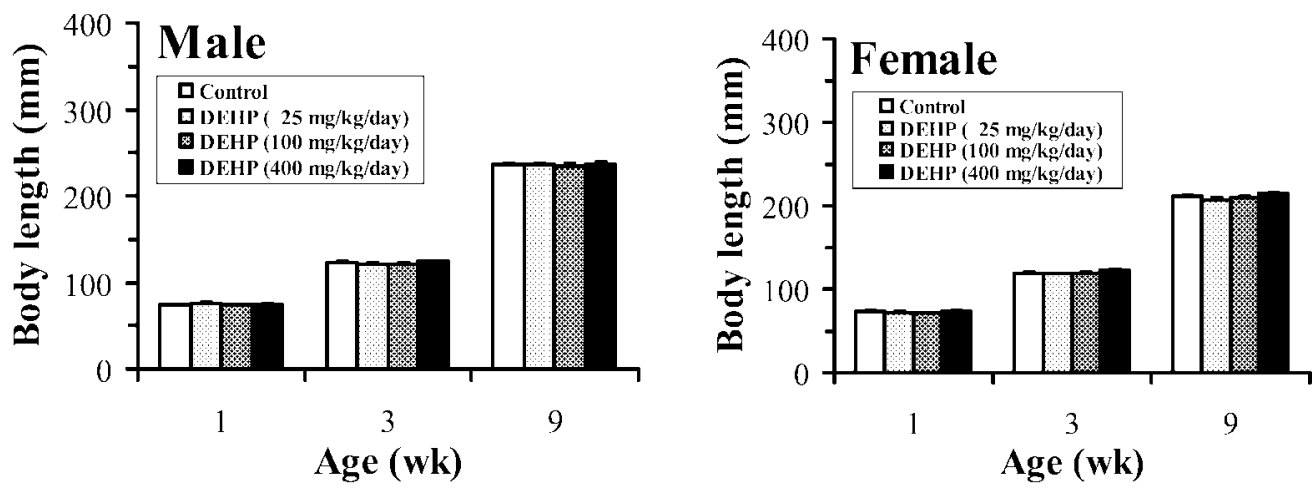

Fig. 3. Effects of maternal exposure to DEHP on postnatal body length of offspring.

Body lengths (nose to anus) of males (left panel) and females (right panel) are shown at 1,3 and 9 wk of age. Each column and vertical bar represent the mean and SEM, respectively. There were no significant differences among groups.
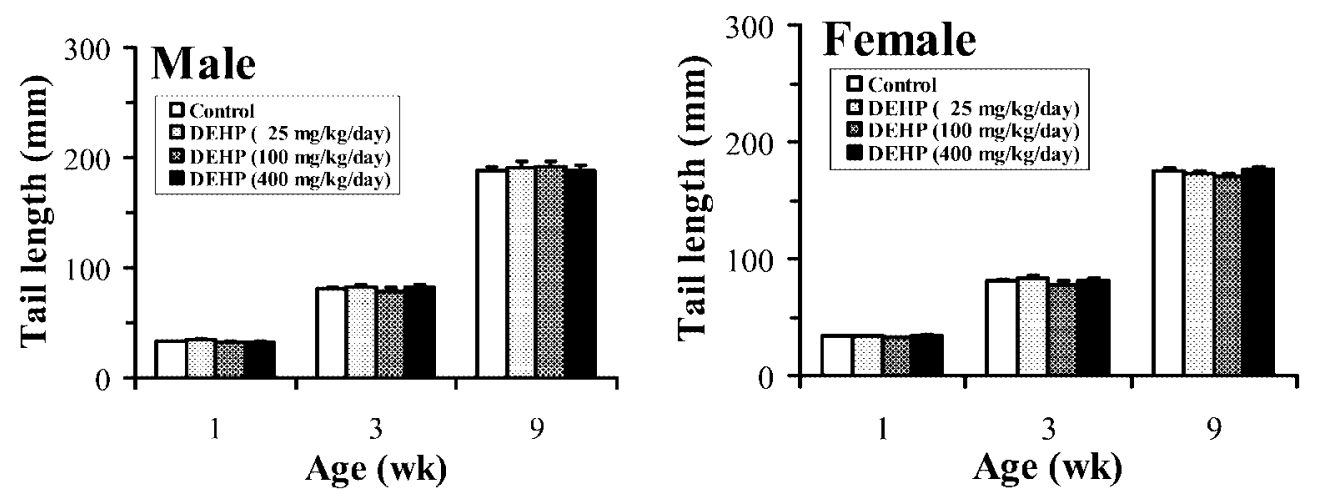

Fig. 4. Effects of maternal exposure to DEHP on postnatal tail length of offspring.

Tail lengths of males (left panel) and females (right panel) are shown at 1,3 and 9 wk of age. Each column and vertical bar represent the mean and SEM, respectively. There were no significant differences among groups. 
Table 3. Organ weights in male offspring

\begin{tabular}{|c|c|c|c|c|c|}
\hline \multirow[t]{2}{*}{ Organ } & \multirow[t]{2}{*}{ Group } & \multirow{2}{*}{$\begin{array}{l}\text { DEHP dose } \\
\text { ( } \mathrm{mg} / \mathrm{kg} / \text { day })\end{array}$} & \multicolumn{3}{|c|}{ Age (wk) } \\
\hline & & & 1 & 3 & 9 \\
\hline \multirow[t]{4}{*}{ Liver (g) } & Control & 0 & $0.372 \pm 0.011^{\mathrm{a}}$ & $1.974 \pm 0.090$ & $15.55 \pm 0.439$ \\
\hline & DEHP & 25 & $0.367 \pm 0.024$ & $1.984 \pm 0.156$ & $16.73 \pm 0.560$ \\
\hline & DEHP & 100 & $0.334 \pm 0.016$ & $1.936 \pm 0.138$ & $14.78 \pm 0.735$ \\
\hline & DEHP & 400 & $0.372 \pm 0.037$ & $2.276 \pm 0.122$ & $15.83 \pm 0.691$ \\
\hline \multirow[t]{4}{*}{ Kidneys (g) } & Control & 0 & $0.191 \pm 0.004$ & $0.618 \pm 0.018$ & $2.951 \pm 0.093$ \\
\hline & DEHP & 25 & $0.188 \pm 0.008$ & $0.585 \pm 0.037$ & $3.049 \pm 0.124$ \\
\hline & DEHP & 100 & $0.164 \pm 0.007$ & $0.582 \pm 0.042$ & $2.842 \pm 0.078$ \\
\hline & DEHP & 400 & $0.163 \pm 0.015$ & $0.632 \pm 0.024$ & $3.071 \pm 0.092$ \\
\hline \multirow[t]{4}{*}{ Testes (g) } & Control & 0 & - b & $0.222 \pm 0.009$ & $3.065 \pm 0.095$ \\
\hline & DEHP & 25 & - & $0.225 \pm 0.014$ & $2.999 \pm 0.102$ \\
\hline & DEHP & 100 & - & $0.213 \pm 0.011$ & $2.834 \pm 0.050$ \\
\hline & DEHP & 400 & - & $0.241 \pm 0.012$ & $3.070 \pm 0.092$ \\
\hline \multirow[t]{4}{*}{ Prostate (g) } & Control & 0 & - & - & $0.443 \pm 0.026$ \\
\hline & DEHP & 25 & - & - & $0.428 \pm 0.033$ \\
\hline & DEHP & 100 & - & - & $0.372 \pm 0.032$ \\
\hline & DEHP & 400 & - & - & $0.358 \pm 0.026$ \\
\hline \multirow[t]{4}{*}{ Seminal vesicles (g) } & Control & 0 & - & - & $1.109 \pm 0.057$ \\
\hline & DEHP & 25 & - & - & $1.064 \pm 0.060$ \\
\hline & DEHP & 100 & - & - & $0.979 \pm 0.034$ \\
\hline & DEHP & 400 & - & - & $1.014 \pm 0.096$ \\
\hline
\end{tabular}

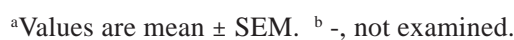

environmental exposure, and the duration of dosing was limited to the period of gestation. The present study was thus designed to investigate whether in utero and lactational exposure to DEHP affects the development of the next generation. For the main study, we set the highest dose at $400 \mathrm{mg} / \mathrm{kg} / \mathrm{day}$ to avoid the influence of maternal toxicity and observe the effect of DEHP on the offspring. The exposure period was prolonged to examine the effects of lactational exposure in addition to the effects of gestational exposure. The offspring of dams in which no overt toxicity was observed $(0,25,100$ and $400 \mathrm{mg} / \mathrm{kg} /$ day $)$, as determined by body weight and general behavior during gestation and lactation, were used in our study.

In recent years, certain studies have focused on the effects of DEHP and its antiandrogenic action on the hypothalamuspituitary-gonadal axis ${ }^{16,17,29)}$; very few studies, however, have reported the effect of DEHP on longer term postnatal development. Hence, it is important to examine the developmental toxicity of DEHP from birth until puberty. In this regard, our study was performed to evaluate the effects of in utero and lactational exposure to DEHP in rat offspring with a special focus on postnatal growth and physical status. We found that somatic and tissue growth and related endocrine landmarks were not affected by DEHP exposure.
Liver weights were slightly increased in the $400 \mathrm{mg} /$ $\mathrm{kg}$ /day group for both male and female offspring at $3 \mathrm{wk}$ of age, but no significant differences were observed among treatment groups. DEHP and other phthalates, such as di(2ethylhexyl) adipate (DEHA) and butylbenzyl phthalate, are peroxisome proliferators that activate peroxisome proliferator-activated receptors and cause liver enlargement ${ }^{23)}$. Induction of peroxisome proliferatoractivated receptors could result in liver enlargement following DEHP exposure (Table 3, 4). This phenomenon could be an adaptive response following consecutive exposures to DEHP. However, this trend was no longer apparent at $9 \mathrm{wk}$ of age. Since the DEHP groups were not exposed to the compound after $3 \mathrm{wk}$ of age, body burden might be decreased because of metabolic clearance.

In a study of reproductive and accessory organ development following DEHP exposure, dose-dependent reductions in ventral, dorsolateral and/or anterior prostate weight were reported in rat offspring on PND 21 and PND 63 in response to oral administration of $\operatorname{DEHP}(0,375,750$ and $1,500 \mathrm{mg} / \mathrm{kg} / \mathrm{day}, \mathrm{GD} 3-\mathrm{PND} 21)^{16)}$. This study also showed that DEHP significantly reduced testis weight on PND 21 and PND 63 in a dose-dependent manner. In the present study, on the other hand, testis weights were not 
Table 4. Organ weights in female offspring

\begin{tabular}{llcccc}
\hline \multirow{2}{*}{ Organ } & Group & $\begin{array}{c}\text { DEHP dose } \\
(\mathrm{mg} / \mathrm{kg} / \mathrm{day})\end{array}$ & \multicolumn{3}{c}{ Age (wk) } \\
\cline { 3 - 6 } & & & 1 & 3 & 9 \\
\hline Liver (g) & Control & 0 & $0.338 \pm 0.007^{\mathrm{a}}$ & $1.899 \pm 0.117$ & $9.665 \pm 0.573$ \\
& DEHP & 25 & $0.322 \pm 0.015$ & $1.886 \pm 0.103$ & $9.279 \pm 0.511$ \\
& DEHP & 100 & $0.349 \pm 0.014$ & $1.808 \pm 0.105$ & $9.760 \pm 0.505$ \\
& DEHP & 400 & $0.367 \pm 0.030$ & $2.046 \pm 0.092$ & $9.643 \pm 0.441$ \\
Kidneys (g) & Control & 0 & $0.176 \pm 0.006$ & $0.605 \pm 0.026$ & $2.039 \pm 0.078$ \\
& DEHP & 25 & $0.177 \pm 0.006$ & $0.593 \pm 0.025$ & $1.849 \pm 0.091$ \\
& DEHP & 100 & $0.179 \pm 0.007$ & $0.583 \pm 0.023$ & $1.983 \pm 0.055$ \\
& DEHP & 400 & $0.171 \pm 0.007$ & $0.583 \pm 0.020$ & $1.959 \pm 0.039$ \\
Ovaries (mg) & Control & 0 & - & $18.95 \pm 0.76$ & $79.57 \pm 4.08$ \\
& DEHP & 25 & - & $17.80 \pm 1.98$ & $74.28 \pm 8.14$ \\
& DEHP & 100 & - & $14.83 \pm 1.83$ & $71.00 \pm 4.26$ \\
& DEHP & 400 & - & $16.67 \pm 0.82$ & $73.42 \pm 3.29$ \\
Uterus (mg) & Control & 0 & - & $26.03 \pm 1.91$ & $327.4 \pm 25.3$ \\
& DEHP & 25 & - & $30.72 \pm 3.95$ & $300.7 \pm 14.2$ \\
& DEHP & 100 & - & $31.96 \pm 2.37$ & $376.3 \pm 30.9$ \\
& DEHP & 400 & - & $27.82 \pm 2.15$ & $340.5 \pm 16.1$ \\
\hline
\end{tabular}

avalues are mean \pm SEM. ${ }^{b}-$, not examined.

Table 5. Hormone determinations in male offspring at $9 \mathrm{wk}$ of age

\begin{tabular}{|c|c|c|c|c|}
\hline \multirow[t]{2}{*}{ Parameter } & \multicolumn{4}{|c|}{ DEHP dose (mg/kg/day) } \\
\hline & 0 & 25 & 100 & 400 \\
\hline$(\mathrm{ng} / \mathrm{ml})$ & $83.1 \pm 6.9^{\mathrm{a}}$ & $74.1 \pm 3.7$ & $73.2 \pm 4.7$ & $81.2 \pm 7.5$ \\
\hline$(\mathrm{ng} / \mathrm{ml})$ & $1.74 \pm 0.05$ & $1.70 \pm 0.06$ & $1.63 \pm 0.07$ & $1.81 \pm 0.09$ \\
\hline$(\mathrm{ng} / \mathrm{ml})$ & $140.0 \pm 35.3$ & $137.3 \pm 30.2$ & $130.5 \pm 16.3$ & $96.5 \pm 19.5$ \\
\hline IGF-I (ng/ml) & $669.6 \pm 49.0$ & $641.7 \pm 57.8$ & $758.6 \pm 49.6$ & $743.5 \pm 23.8$ \\
\hline
\end{tabular}

aValues are mean \pm SEM.

Table 6. Hormone determinations in female offspring at $9 \mathrm{wk}$ of age

\begin{tabular}{|c|c|c|c|c|}
\hline \multirow[t]{2}{*}{ Parameter } & \multicolumn{4}{|c|}{ DEHP dose (mg/kg/day) } \\
\hline & 0 & 25 & 100 & 400 \\
\hline$(\mathrm{ng} / \mathrm{ml})$ & $70.0 \pm 7.4^{\mathrm{a}}$ & $70.7 \pm 5.4$ & $67.7 \pm 4.8$ & $69.1 \pm 6.4$ \\
\hline$(\mathrm{ng} / \mathrm{ml})$ & $1.88 \pm 0.11$ & $1.91 \pm 0.06$ & $1.76 \pm 0.06$ & $1.79 \pm 0.10$ \\
\hline $\mathrm{GH} \quad(\mathrm{ng} / \mathrm{ml})$ & $98.4 \pm 9.6$ & $99.5 \pm 19.6$ & $121.3 \pm 22.4$ & $109.4 \pm 19.4$ \\
\hline IGF-I (ng/ml) & $499.0 \pm 34.4$ & $574.0 \pm 34.6$ & $528.6 \pm 42.5$ & $632.6 \pm 66.0$ \\
\hline
\end{tabular}

${ }^{a}$ Values are mean \pm SEM.

significantly different between the control and DEHP groups. No significant differences in prostate weights were observed among the groups, although they were reduced in a dosedependent manner (Table 3). The outcomes of the present study at the highest dose $(400 \mathrm{mg} / \mathrm{kg} /$ day $)$ were in accordance with those of Moore et al., who conducted a study that used $375 \mathrm{mg} / \mathrm{kg} / \mathrm{day}$ as the lowest dose ${ }^{16)}$. The magnitude of DEHP effects in the present study was much smaller than that found in the study by Moore et al. ${ }^{16}$; this discrepancy could be explained by the large difference in dosage range.

Thyroid hormones play pivotal roles in normal growth, neuronal development and metabolism in animals. Endocrine disturbance following chemical exposure is suspected to occur at the embryonic and/or neonatal stage rather than at 
the adult stage. An epidemiological study has suggested that toxicants such as polychlorinated biphenyls and dioxins, which are persistent and cumulative compounds in the environment, may affect growth and development through thyroid impairment ${ }^{24)}$. Animal studies have reported that 2,3,7,8-tetracholorodibenzo- $p$-dioxin disrupts thyroid homeostasis ${ }^{25)}$ and causes developmental defects ${ }^{26}$ and bone growth deficits ${ }^{27)}$. Thyroid hormones are hormonal regulators of bone growth. The principal hormonal regulators during postnatal development are GH and IGF-I, and these hormones, which are regulated by thyroid hormones, are considered biomarkers for longitudinal somatic growth ${ }^{28)}$. In the present study, hormonal parameters regarding developmental somatic growth were determined in the offspring to better assess the physical status following DEHP exposure. There were no significant differences in any parameters in male and female rat offspring (Table 5, 6). The fact that normal hormonal parameters were observed in rat offspring following exposure of dams to DEHP (even at high doses) leads us to conclude that postnatal development remains intact in the offspring.

The level of DEHP exposure used in the present study was much greater $(\sim 1,000$-fold higher) than the estimated intake due to either medical exposure or consumer exposure in adult humans ${ }^{3)}$. It was recently suggested that the magnitude of testicular toxicity after DEHP exposure is associated with the duration and/or the route of exposure ${ }^{14,}$ 29). Inhalation of DEHP caused an elevation of plasma testosterone without affecting gonadotropin and several steroid enzymes that are involved in testosterone synthesis in male prepubertal rats ${ }^{14)}$. These findings suggest that levels of DEHP that cause hormonal disturbance when inhaled may not have the same effect if consumed orally.

In conclusion, our results suggest that prenatal and postnatal exposure to DEHP does not affect postnatal somatic growth or endocrine and physical status of either males or females under the experimental conditions we used. The effects of DEHP exposure, however, remain uncertain and must be clarified using a wider dosage range, an extended exposure period, a side-by-side comparison of different exposure routes and a larger number of animals.

\section{Acknowledgements}

The authors thank Mr. T. Murase, Ms. S. Watanabe and Mr. S. Numajiri for their help throughout this study. This study was conducted as a part of contract research with the Ministry of Health, Labour and Welfare, which was supported by funds from the Ministry of the Environment.

\section{References}

1) NTP-CERHR (2000) CERHR Expert panel report on di(2ethylhexyl) phthalate. National Toxicology Program, U.S. Department of Health and Humane Services.

2) EHC 131. Diethylhexyl phthalate. Environmental Health Criteria 131, The International Programme on Chemical Safety, WHO, Geneva. http://www.inchem.org/documents/ ehc/ehc/ehc131.htm. Accessed June 5, 2006.

3) Clark K, Cousins I, Mackay D (2003) Assessment of Critical Exposure Pathways. In: The handbook of environmental chemistry, Vol. 3, Part Q, Phthalate esters, Staples CA (Ed.), 227-62, Springer-Verlag, Berlin.

4) Shiota K, Chou MJ, Nishimura H (1980) Embryotoxic effects of di-2-ethylhexyl phthalate (DEHP) and di-n-butyl phthalate (DBP) in mice. Environ Res 22, 245-53.

5) Shiota K, Nishimura H (1982) Teratogenicity of di(2ethylhexyl) phthalate (DEHP) and di-n-butyl phthalate (DBP) in mice. Environ Health Perspect 45, 65-70.

6) Shiota K, Miwa S (1985) Assessment of the teratogenicity of di (2-ethylhexyl) phthalate and mono (2-ethylhexyl) phthalate in mice. Arch Toxicol 56, 263-6.

7) Tomita I, Nakamura Y, Yagi Y, Tutikawa K (1982) Teratogenicity/fetotoxicity of DEHP in mice. Environ Health Perspect 45, 71-5.

8) Tyl RW, Price CJ, Marr MC, Kimmel CA (1988) Developmental toxicity evaluation of dietary di(2ethylhexyl)phthalate in Fischer 344 rats and CD-1 mice. Fundam Appl Toxicol 10, 395-412.

9) Singh WR, Lawrence WH, Autian J (1972) Teratology of phthalate esters in rat. J Pharm Sci 61, 51-5.

10) Lewandowski M, Fernandes J, Chen TS (1980) Assessment of the teratogenic potential of plasma-soluble extracts of diethylhexyl phthalate plasticized polyvinyl chloride plastics. Toxicol Appl Pharmacol 54, 141-7.

11) Poon R, Lecavalier P, Mueller R, Valli VE, Procter BG, Chu I (1997) Subchronic oral toxicity of di-n-octyl phthalate and di (2-ethylhexyl) phthalate in the rat. Food Chem Toxicol 35, 225-39.

12) Gray LE Jr, Ostby J, Furr J, Price M, Veeramachaneni DN, Parks L (2000) Perinatal exposure to the phthalates DEHP, BBP, and DINP, but not DEP, DMP, or DOTP, alters sexual differentiation of the male rat. Toxicol Sci 58, 350-65.

13) Agarwal DK, Eustis S, Lamb JC 4th, Reel JR, Kluwe WM (1986) Effects of di(2-ethylhexyl) phthalate on the gonadal pathophysiology, sperm morphology, and reproductive performance of male rats. Environ Health Perspect 65, 343-50.

14) Kurahashi N, Kondo T, Omura M, Umemura T, Ma M, Kishi $\mathrm{R}$ (2005) The effects of subacute inhalation of di (2ethylhexyl) phthalate (DEHP) on the testes of prepubertal Wistar rats. J Occup Health 47, 437-44.

15) Davis BJ, Maronpot RR, Heindel JJ (1994) Di-(2-ethylhexyl) phthalate suppresses estradiol and ovulation in cycling rats. Toxicol Appl Pharmacol 128, 216-23.

16) Moore RW, Rudy TA, Lin T-M, Ko K, Peterson RE (2001) 
Abnormalities of sexual development in male rats with in utero and lactational exposure to the antiandrogenic plasticizer di(2-ethylhexyl)phthalate. Environ Health Perspect 109, 229_ 37.

17) Akingbemi BT, Youker RT, Sottas CM, Ge R, Katz E, Klinefelter GR, Zirkin BR, Hardy MP (2001) Modulation of rat Leydig cell steroidogenic function by di(2ethylhexyl)phthalate. Biol Reprod 65, 1252-9.

18) Kobayashi K, Miyagawa M, Wang RS, Sekiguchi S, Suda M, Honma T (2002) Effects of in utero and lactational exposure to bisphenol A on somatic growth and anogenital distance in $\mathrm{F}_{1}$ rat offspring. Ind Health 40, 375-81.

19) Nagel SC, vom Saal FS, Thayer KA, Dhar MG, Boechler M, Welshons WV (1997) Relative binding affinity-serum modified access (RBA-SMA) assay predicts the relative in vivo bioactivity of the xenoestrogens bisphenol $\mathrm{A}$ and octylphenol. Environ Health Perspect 105, 70-6.

20) vom Saal FS, Cooke PS, Buchanan DL, Palanza P, Thayer KA, Nagel SC, Parmigiani S, Welshons WV (1998) A physiologically based approach to the study of bisphenol A and other estrogenic chemicals on the size reproductive organs, daily sperm production, and behavior. Toxicol Ind Health 14, 239-60.

21) Ashby J, Tinwell H, Haseman J (1999) Lack of effects for low dose levels of bisphenol A and diethylstilbestrol on the prostate gland of CF1 mice exposed in utero. Regul Toxicol Pharmacol 30, 156-66.

22) Cagen SZ, Waechter JM Jr, Dimond SS, Breslin WJ, Butala JH, Jekat FW, Joiner RL, Shiotsuka RN, Veenstra GE, Harris
LR (1999) Normal reproductive organ development in CF1 mice following prenatal exposure to bisphenol A. Toxicol Sci 50, 36-44.

23) Kersten S, Wahli W (2000) Peroxisome proliferator activated receptor agonists. EXS 89, 141-51.

24) Koopman-Esseboom C, Morse DC, Weisglas-Kuperus N, Lutkeschipholt IJ, Van der Paauw CG, Tuinstra LG, Brouwer A, Sauer PJ (1994) Effects of dioxins and polychlorinated biphenyls on thyroid hormone status of pregnant women and their infants. Pediatr Res 36, 468-73.

25) Nishimura N, Yonemoto J, Miyabara Y, Sato M, Tohyama C (2003) Rat thyroid hyperplasia induced by gestational and lactational exposure to 2,3,7,8-tetrachlorodibenzo-p-dioxin. Endocrinology 144, 2075-83.

26) Pohjanvirta R, Tuomisto J (1994) Short-term toxicity of 2,3,7,8-tetrachlorodibenzo-p-dioxin in laboratory animals: effects, mechanisms, and animal models. Pharmacol Rev 46, 483-549.

27) Miettinen HM, Pulkkinen P, Jamsa T, Koistinen J, Simanainen U, Tuomisto J, Tuukkanen J, Viluksela M (2005) Effects of in utero and lactational TCDD exposure on bone development in differentially sensitive rat lines. Toxicol Sci 85, 1003-12.

28) Ohlsson C, Bengtsson BA, Isaksson OG, Andreassen TT, Slootweg MC (1998) Growth hormone and bone. Endocr Rev 19, 55-79.

29) Akingbemi BT, Ge R, Klinefelter GR, Zirkin BR, Hardy MP (2004) Phthalate-induced Leydig cell hyperplasia is associated with multiple endocrine disturbances. Proc Natl Acad Sci USA 101, 775-80. 